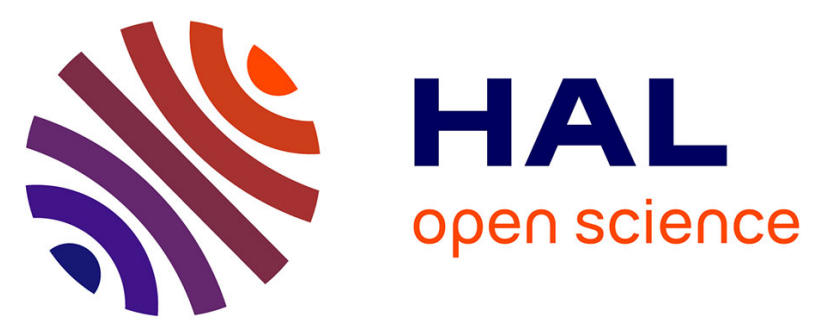

\title{
Black Sesame Seeds Ethanol Extract Ameliorates Hepatic Lipid Accumulation, Oxidative Stress, and Insulin Resistance in Fructose-Induced Nonalcoholic Fatty Liver Disease
}

\author{
Yang Yang, Jingjing Wang, Yongmin Zhang, Jing Li, Wenji Sun
}

\section{To cite this version:}

Yang Yang, Jingjing Wang, Yongmin Zhang, Jing Li, Wenji Sun. Black Sesame Seeds Ethanol Extract Ameliorates Hepatic Lipid Accumulation, Oxidative Stress, and Insulin Resistance in FructoseInduced Nonalcoholic Fatty Liver Disease. Journal of Agricultural and Food Chemistry, 2018, 66 (40), pp.10458-10469. 10.1021/acs.jafc.8b04210 . hal-01949427

\section{HAL Id: hal-01949427 \\ https://hal.sorbonne-universite.fr/hal-01949427}

Submitted on 10 Dec 2018

HAL is a multi-disciplinary open access archive for the deposit and dissemination of scientific research documents, whether they are published or not. The documents may come from teaching and research institutions in France or abroad, or from public or private research centers.
L'archive ouverte pluridisciplinaire HAL, est destinée au dépôt et à la diffusion de documents scientifiques de niveau recherche, publiés ou non, émanant des établissements d'enseignement et de recherche français ou étrangers, des laboratoires publics ou privés. 
1 Black Sesame Seeds Ethanol Extract Ameliorates Hepatic Lipid

2 Accumulation, Oxidative Stress and Insulin Resistance in

3 Fructose-induced Nonalcoholic Fatty Liver Disease (NAFLD)

$4 \quad$ Yang Yang ${ }^{\dagger}, \S$, Jingjing Wang ${ }^{\dagger}, \S$, Yongmin Zhang ${ }^{\dagger}, \S, \#$, Jing Li $^{\dagger}, \S$, Wenji Sun ${ }^{\dagger,}$

$5{ }^{\dagger}$ Key Laboratory of Resource Biology and Biotechnology in Western China

6 (Northwest University), Ministry of Education, Xi'an 710069, China

7 \$Biomedicine Key Laboratory of Shaanxi Province, College of Life Sciences,

$8 \quad$ Northwest University, Xi'an 710069, China

9 "Sorbonne Université, Institut Parisien de Chimie Moléculaire, CNRS UMR 8232, 4

10 place Jussieu, 75005 Paris, France

11

12

13

14

15

16

17

18

19

20

21 


\section{ABSTRACT}

The aim of the present study was to investigate the effect of black sesame seeds ethanol extract (BSSEE) against nonalcoholic fatty liver disease (NAFLD) in fructose-fed mice. Mice were fed diet without or with 30\% fructose for 8 consecutive weeks, while mice in three BSSEE tested groups received different dose of BSSEE $(0.5,1$ and $2 \mathrm{~mL} / \mathrm{kg})$ once a day from the 5 th week to the 8th weeks. Administration of BSSEE dose-dependently exerted antiobesity and protective effect against metabolism disorder in fructose-fed mice. Liver histological results indicated that administration of BSSEE significantly reduced hepatic lipid accumulation. Insulin tolerance tests (ITT) and glucose tolerance tests (GTT) along with decrease of serum insulin and glucose levels by BSSEE treatment suggested the improvement of body insulin resistance, and administration of 1 and $2 \mathrm{~mL} / \mathrm{kg}$ BSSEE mitigated liver insulin resistance as the evidence of down-regulated expressions of phospho-JNK1, phospho-NF-kB p65, phospho-IRS1 (Ser 307) and phospho-IKK, and up-regulated XBP1 expression, as well as reductions of hepatic TNF- $\alpha$ and IL-6 levels. In addition, BSSEE treatment reduced hepatic oxidative stress through increasing GSH, vitamin C and Nrf2 levels, enhancements of SOD, CAT and GSH-Px activities, and decreasing MDA and NO levels. These results demonstrated that black sesame seeds showed good effects against NAFLD-related metabolic diseases in fructose-fed mice, and may be a potent dietary supplements in the prevention of the diseases.

KEYWORDS: black sesame seeds, nonalcoholic fatty liver disease, fructose, insulin tolerance, hepatic oxidative stress. 


\section{- INTRODUCTION}

Nonalcoholic fatty liver disease (NAFLD) comprises a wide pathologic spectrum of liver pathologies ranging from steatosis to steatohepatitis, fibrosis, cirrhosis and even hepatocellular carcinoma, which is characterized by the common central feature of the fatty degeneration in liver cells ${ }^{1}$. Nowadays, the disease is considered as one of the most prevalent chronic liver disease all over the world with a reported prevalence ranging $20-30 \%$ according to the studied populations ${ }^{2}$. The important reasons for this high prevalence is closely associated with the increasing prevalence of obesity, diabetes and metabolic syndrome ${ }^{3}$. Although the molecular mechanisms involved in the pathopoiesis of NAFLD are not clearly understood, it has been found that impaired insulin function is a very risk factor in the development of NAFLD. In the progression of NAFLD, pro-infiammatory cytokines such as tumor necrosis factor alpha (TNF- $\alpha$ ) and interleukin-6 (IL-6) that drive insulin resistance is closely linked with the aggravation of NAFLD through activation of specific intracellular signalling pathways, involving in not only the c-Jun NH2-terminal kinase 1 (JNK1), iкB kinase (IKK), nuclear factor kappa B (NF-кB), x-box binding protein 1 (XBP1), but also reactive oxygen species (ROS) and free fatty acids (FFA), where all these pathways could interact with insulin signalling via serine/threonine inhibitory phosphorylation of insulin receptor substrate 1 (IRS1) ${ }^{4}$. Notably, some food supplement is rich in antioxidants and have good anti-inflammatory effect, which may be more beneficial in prevention of NAFLD.

Fructose is one of main sugars consumption in diet. In the United States, Europe 
and China, high-fructose corn syrup (HFSC), containing more than $42 \%$ fructose, has became a replacement of refined sugar in many foods and most sweetened beverages, such as soft drinks, juice beverages, canned fruits, jellies, jams, breakfast cereals and baked goods 5 . Fructose intake can cause more productions of glucose, glycogen, lactate and pyruvate, which contribute to the formation of triglycerides in liver cells 5 , ${ }^{6}$. Further studies indicated that high-fructose diets activates lipogenesis at least partly linked to insulin resistance ${ }^{5,7}$. In addition, dietary high fructose facilitates oxidative damage in various tissues. More production of ROS has been claimed as a persistent contributor for liver cell damage and impaired glucose tolerance in fructose-induced NAFLD ${ }^{8-11}$. Long term intake of high fructose has been repeatedly proved to be a risk factor for the pathopoiesis of NAFLD both in animals and human $5,8,10$.

Sesame seed (sesamum indicum L.) is one of the world's most important and oldest oil seed crops known to humanity ${ }^{12}$. Sesame seeds and its oil are popularly used in cookery to flavour foods and drinks ${ }^{13}$. Notably, sesame seed have many species (most being white sesame seeds and brown (golden) sesame seeds), one of which is black sesame seeds. The black sesame are rich in fatty oil, containing mainly oleic acid and linoleic acid, and other chemical constituents including sesamin, sesamolin, sesamol, vitamin E, phytosterols, lecithin, pedaliin, protein and minerals ${ }^{14}$. The black sesame seeds are more flavorful and have a stronger aroma than white or brown sesame seeds. Toasting black sesame seeds releases beneficial chemicals as well as enhancing the flavor. In addition, black sesame seeds are believed to have medicinal properties. In China, black sesame seeds is superior to other species as food 
for health and often acts as a traditional Chinese medicine for promoting shiny and dark hair, invigorating liver and kindy, benefiting life essence, nourishing blood and moistening the intestines ${ }^{14}$. In addition, a comparative study found that black sesame seeds showed potent antioxidant activity than white sesame seeds ${ }^{15-17}$. It is worth mentioning that sesame oil mainly from white or brown sesames ${ }^{18,19}$, as well as its phytochemical compounds such as sesamin ${ }^{20-22}$, sesamolin ${ }^{23,24}$ and sesamol ${ }^{25,26}$, have been reported that they show hepatoprotective effect and can alleviate steatosis in steatohepatitis by regulating lipid metabolism and enhancing anti-oxidative stress effect in animals 18-21, 24, 25. However, limited studies have been performed on the investigation of the protective effect of black sesame seeds against NAFLD and its molecular biological mechanism in fructose-induced NAFLD. Since the high prevalence of NAFLD and lack of satisfactory treatments, finding the best diet to replace therapies may be a good choice for preventing and treating the disease. Therefore, the aim of the present study was to investigate the effect of black sesame seeds ethanol extract (BSSEE) against NAFLD-related metabolic diseases.

\section{- MATERIALS AND METHODS}

\section{BSSEE Extraction and Main Ingredient Analysis.}

Black sesame seeds (sesamum indicum L.) were obtained from Yurun Global Sourcing Center for Agricultural Products (Xi'an, Shaanxi, China), and pulverized using a Chinese herbal remedier (FW117, Nanchang Jiedao Scientific Instruments Co., Ltd., Jiangxi, China). $1 \mathrm{~kg}$ of this powder was extracted with $10000 \mathrm{~mL}$ of $95 \%$ ethanol (Analytical grade, Xi'an Chemical Reagent Factory, Shaanxi, China) at $25^{\circ} \mathrm{C}$ 
and repeated three times. The ethanol extract was concentrated on a rotavapor (RE52CS-1, Shanghai Yarong Biochemical Instrument Factory, Shanghai, China) at $50{ }^{\circ} \mathrm{C}$. Then $20.2 \mathrm{~mL}$ of the crude extract was obtained and stored at $-20{ }^{\circ} \mathrm{C}$ for the analysis, and $1 \mathrm{~mL}$ of this extract weights $0.83 \mathrm{~g}$. The yield of the obtained the black sesame seeds ethanol crude extract (BSSEE) from fresh black sesame seeds was $1.68 \%(\mathrm{w} / \mathrm{w})$, calculated by the weight of the seeds used in the extraction procedure.

BSSEE were analyzed using a LiChrosorb $\mathrm{C}_{18}$ column $(4.6 \mathrm{~mm}$ i.d. $\times 250 \mathrm{~mm}, 5$ $\mu \mathrm{m}$, Merck, Darmstadt, Germany) in the analytical high performance liquid chromatography (HPLC) instrument (Waters 2695 HPLC system equipped with a PDA detector was used in addition to an Empower chromatographic workstation, Waters Corporation, Milford, Massachusetts, USA). Chromatographic separation was performed using an gradient elution at a flow rate of $1.0 \mathrm{~mL} / \mathrm{min}$ with mobile phase for (A) methanol (HPLC grade, Merck, Darmstadt, Germany)/(B) distilled water: 30-100\% A ( 0-60 min). The column temperature was controlled at $30{ }^{\circ} \mathrm{C}$, and the effluents were monitored at $280 \mathrm{~nm} .0 .1 \mathrm{~mL}$ of the black sesame seeds extract was dissolved in $1 \mathrm{~mL}$ methanol (Analytical grade, Xi'an Chemical Reagent Factory, Shaanxi, China) and filtered with $0.20 \mu \mathrm{m}$ Nylon filter (Beijing Kaiyuan Guochuang technology Co., Ltd., Beijing, China), and then $20 \mu \mathrm{l}$ of the dilute solution was injected for analysis. Calibration curves were constructed with reference standards and used to determine the concentrations of sesaminol, sesamin and sesamolin in BSSEE. Sesaminol, sesamin and sesamolin (Purity $\geq 97 \%$ ) were purchased from Sigma-Aldrich Corp. (St. Louis, MO, USA). As shown in the Figure 1, the three 
major components of BSSEE, sesaminol (1.92\%), sesamin (16.33\%) and sesamolin $(13.06 \%)$ accounted for $31.31 \%$ of the total extract. This result is similar to previous studies ${ }^{26}$.

\section{Animals and Experimental Design.}

Fifty healthy adult male kunming mice $(20 \pm 3 \mathrm{~g})$ were purchased from the Experimental Animal Center, Xi'an Jiaotong University (SCXK2012-003, Xi'an, Shaanxi, China). Animals were housed at standard conditions: normal light/dark (12h/12h) cyclic conditions and $25 \pm 3{ }^{\circ} \mathrm{C}, 30-70 \%$ humidity. Use of the mice was reviewed and approved by both Northwest University and the local animal Ethics Committee.

Mice in all groups were fed a standard diet (Jiangsu Cooperative Medical Biological Engineering Co., Ltd., Nanjing, Jiangsu, China). The composition of diet was as follows: $63 \%$ carbohydrate, $18 \%$ crude protein, $5 \%$ crude fat, $3 \%$ crude fiber, $6 \%$ ash and 5\% predefined minerals plus amino acids and vitamins. Representative ingredients of diet are ground wheat, ground corn, dehulled soybean meal, corn gluten meal, fish meal, chicken meal, soybean oil, methionine, lysine, cystine, calcium carbonate, brewers dried yeast, dicalcium phosphate and iodized salt. The energy content of the diet was $3.64 \mathrm{kcal} / \mathrm{g}$. BSSEE was prepared into soybean oil (Zhejiang Tian Yushan Medicinal Oils Co., Ltd., Quzhou, Zhejiang, China) before administration to the mice. Animals were acclimated to housing conditions for one week. Subsequently mice were randomly divided into 5 groups with 10 each, including the control group, fructose group and three fructose $+\operatorname{BSSEE}(0.5,1$ and 2 
$\mathrm{mL} / \mathrm{kg}$ ) tested groups. Except for the mice in the control group freely drank water without fructose, mice in all groups freely drank water containing $30 \%$ fructose (Shanghai Yuanye Biotechnology Co., Ltd., Shanghai, China) for 8 consecutive weeks (From the 1st week to the 8th week). However, animals in those fructose + BSSEE $(0.5,1$ and $2 \mathrm{~mL} / \mathrm{kg})$ tested groups received different dose of BSSEE $(0.5,1$ and 2 $\mathrm{mL} / \mathrm{kg}$ ) by intragastric administration once a day at the end of the 4 th week for 4 consecutive weeks (From the 5th week to the 8th week) respectively, while mice in the control group and the fructose group received the same amount of soybean oil. During the whole experimental period, the body weight of each mouse was noted at three days intervals, and food intake and water consumption in each group was recorded every day.

On the last day, at the end of the drug administration, mice in all groups were fasted for 8 hours. Then all animals were anesthetized and blood of each mouse was collected through retro-orbital plexus. Subsequently all animals were euthanized, and the liver, epididymal adipose, subcutaneous adipose and perirenal adipose were collected and weighed. The liver of each mouse were collected and cut into two parts, with one part of liver lobe immersed in $4 \%$ paraformaldehyde solution for histological examinations and immunohistochemistry (IHC), while the other part of liver lobe stored at $-80^{\circ} \mathrm{C}$ for the biochemical analysis.

\section{Serum Biochemical Analysis.}

Serum was separated by centrifugation at $1000 \mathrm{~g}\left(4^{\circ} \mathrm{C}\right)$ for $10 \mathrm{~min}$. The levels of biochemical parameters, including aspartate transaminase (AST), alanine 
176

177

transaminase (ALT), glucose, total cholesterol, and triglycerides, were measured colorimetrically and assayed by an automatic biochemistry analyzer (AU5800, Beckman Coulter, Inc., California, USA). Free fatty acids (FFA) were measured using a commercial kit (BC0590, Solarbio, Beijing, China), and insulin level was measured by a mouse insulin ELISA Kit (TWp001983, Shanghai Tongwei Industrial Co., Ltd., Shanghai, China), in which the results were obtained by a DNM-9602 Reader (Beijing Prang New Technology Co., Ltd., Beijing, China).

\section{Histological Staining.}

Liver tissues were fixed in $4 \%$ paraformaldehyde solution $(137 \mathrm{mM} \mathrm{NaCl}, 10$ $\mathrm{mM} \mathrm{Na} 2 \mathrm{HPO} 4,2 \mathrm{mM} \mathrm{KH} 2 \mathrm{PO} 4$, and $2.7 \mathrm{mM} \mathrm{KCl}, 1000 \mathrm{~mL}$ deionized water, $4 \%$ paraformaldehyde, $\mathrm{pH}$ 7.4) for 24 hours, embedded in paraffin and cut into $5 \mu \mathrm{m}$ sections using YD-1508R Tissue Slicer (Beijing Jiayuan Industrial Technology Co., Ltd., Beijing, China), and then selected good tissue sections were mounted on adhesion microscope slides (Citotest Labware Manufacturing Co., Ltd., Haimen, Jiangsu, China) and stained with hematoxylin \& eosin (H\&E) for the examination of the morphology of liver. In order to evaluate lipid droplet accumulation, liver tissues were treated with $4 \%$ paraformaldehyde solution, embedded in optimal cutting temperature (OCT) compound (Tissue-Tek, Sakura Finetek, Torrance, CA, USA), and frozen sections $(10 \mu \mathrm{m})$ of liver tissues were washed with sterile water, infiltrated with $60 \%$ isopropanol for $2 \mathrm{~min}$, and then stained with oil red $\mathrm{O}$ (Muto Pure Chemicals Co., Ltd., Tokyo, Japan). The severity of liver injury were evaluated by visual estimate under a LIRI-2006 microscope according to the method reported 
198

199

previously ${ }^{27}$ : Ballooning degeneration of hepatocytes: grade $=0(<5 \%)$, grade $=1(5 \%$ $-30 \%)$, grade $=2(30 \%-50 \%)$, grade $=3(50 \% \leq)$; Steatosis: grade $=0(<5 \%)$, grade $=1$ $(5 \%-30 \%)$, grade $=2(30 \%-50)$, grade $=3(50 \% \leq)$. Three sections and 3 fields per tissue were observed ( $n=3$ in each group). Photographs taken from tissue sections were digitized using CMOS camera equipped with a GMS image analysis system (Shanghai optical instrument factory, Shanghai, China).

\section{Insulin Tolerance Tests (ITT) and Glucose Tolerance Tests (GTT)}

GTT (A) and ITT (B) were performed on weeks 7, respectively. In the ITT, mice from all five group were fasted for 8 hours and then injected intraperitoneally with 1 U human insulin/kg body weight, and blood glucose values were measured at ( $0 \mathrm{~min})$ and at 5, 10, 30, 60, and $120 \mathrm{~min}$. For GTT, mice fasted 8 hours were injected intraperitoneally with d-glucose ( $2 \mathrm{~g} / \mathrm{kg}$ body weight), and blood glucose was measured at ( $0 \mathrm{~min})$ and at 5, 15, 30, 90, 60, and $120 \mathrm{~min}$. Glucose levels both in GTT and ITT were measured using a glucometer (Sinocare Inc., Changsha, Hunan, China). The area under the curve (AUC) for GTT and ITT tests were calculated according to the trapezium rule ${ }^{28}$.

\section{Analyses of TNF- $\alpha$ and IL-6 Levels in Liver and Serum.}

TNF- $\alpha$ and IL-6 levels in serum and liver homogenates were determined by commercial ELISA kits (KET7015 and KET7009, Abbkine Scientific Co., Ltd., California, USA), respectively.

\section{Measurement of Hepatic Triglycerides Level}

Liver tissue was homogenized in ice-cold PBS buffer $(137 \mathrm{mM} \mathrm{NaCl}, 10 \mathrm{mM}$ 
$\mathrm{Na}_{2} \mathrm{HPO}_{4}, 2 \mathrm{mM} \mathrm{KH} \mathrm{PO}_{4}$, and $2.7 \mathrm{mM} \mathrm{KCl}, 1000 \mathrm{~mL}$ deionized water, $\mathrm{pH}$ 7.4). Hepatic triglycerides was extracted with the method described by Fossati ${ }^{29}$, and determined on a DNM-9602 Reader (Beijing Perlong New Technology Co., Ltd., Beijing, China) by a assay kit (MAK266-1KT, Sigma-Aldrich Corp., St. Louis, MO, USA).

\section{Hepatic Oxidative Stress Analysis.}

Liver tissues $(100 \mathrm{mg})$ were homogenized with $1 \mathrm{~mL}$ of cold PBS buffer (137 $\mathrm{mM} \mathrm{NaCl}, 10 \mathrm{mM} \mathrm{Na} 2 \mathrm{HPO}_{4}, 2 \mathrm{mM} \mathrm{KH} \mathrm{PO}_{4}$, and $2.7 \mathrm{mM} \mathrm{KCl}, 1000 \mathrm{~mL}$ deionized water, $\mathrm{pH} 7.4$ ) and then centrifuged at $10000 \mathrm{~g}$ for $30 \mathrm{~min}$ at $4{ }^{\circ} \mathrm{C}$. The homogenates were subjected to assays for nitric oxide (NO), vitamin C, glutathione (GSH), glutathione peroxidase (GSH-px), glutathione (GSH), catalase (CAT), superoxide dismutase (SOD), and malondialdehyde (MDA) using commercially available enzymatic assay kits (Wuhan ColorfulGene Biological Technology Co., Ltd., Wuhan, Hubei, China). All data acquisition was performed on an A6 semiautomatic biochemistry analyzer (Beijing Shining Sun Technology Co., Ltd., Beijing, China).

\section{Western Blot Analysis.}

Hepatic protein expressions of phospho-JNK1, phospho-IRS1 (Ser 307), Phospho-IKK alpha/beta (Ser180/181) and XBP1 were evaluated by western blot analysis. Primary antibody against phospho-JNK1 (AF3318), phospho-IRS1 (AF3272), Phospho-IKK alpha/beta (AF3013) and XBP1 (AF5110) were obtained from Affinity Biosciences (Affinity Biosciences, Cincinnati, USA) and used for the western bolt analysis, respectively. Liver tissues were homogenized in 
cold radioimmunoprecipitation assay buffer $(10 \mathrm{mM}$ Tris- $\mathrm{HCl}, \mathrm{pH} 7.4,1 \% \mathrm{w} / \mathrm{v}$ Triton $\mathrm{X}-100,0.1 \% \mathrm{w} / \mathrm{v}$ sodium dodecyl sulfate, $150 \mathrm{mM} \mathrm{NaCl}, 1 \%$ sodium deoxycholate, $1 \mathrm{mM} \mathrm{NaF,} 5 \mathrm{mM}$ EDTA, protease inhibitors, and $1 \mathrm{mM}$ sodium orthovanadate). The lysates were cleared by centrifugation at $15000 \mathrm{~g}$ at $4{ }^{\circ} \mathrm{C}$ for 30 min. The protein concentrations were quantified with a BCA assay kit (Huaying Biotechnology Co., Ltd., Hubei, China). Aliquots of lysates containing 25-40 $\mu \mathrm{g}$ protein were separated by sodium dodecyl sulfate-polyacrylamide gel electrophoresis (SDS-PAGE), and electrophoretically transferred to polyvinylidene difluoride (PVDF) membranes by electrophoretic transfer (Bio-Rad Laboratories, Inc., California, UAS). After blocking with 5\% BSA (0332, Amresco, USA) in TBST buffer (20 mM Tris-base, $150 \mathrm{mM} \mathrm{NaCl}, 0.05 \%$ Tween 20, $\mathrm{pH}$ 8.0) for $2 \mathrm{~h}$ and rinsed three times with TBST buffer for $5 \mathrm{~min}$ each, the membranes were probed overnight at $4{ }^{\circ} \mathrm{C}$ with primary antibodies (Dilution 1:1000), respectively. After removal of the unbound primary antibody with TBST buffer, the membranes were washed and incubated with the secondary horseradish peroxidase-conjugated antibodies (dilution 1:50000, S0001, Affinity Biosciences, Cincinnati, USA) at room temperature for $2 \mathrm{~h}$. Chemiluminescence was visualized using an ECL western blot detection kit (KF001, Affinity Biosciences, Cincinnati, USA). The signal was captured with a UVP BioSpectrum AC imaging system (UVP, Upland, CA, USA). Quantitation of protein expression was evaluated by densitometry using ImageJ software version k1.47 (NIH, Bethesda, MD, USA). $\beta$-actin expression with an anti- $\beta$-actin mouse antibody (YM3028, ImmunoWay Biotechnology Company, Plano, USA) was used as an 
internal control for equal loading of protein.

\section{Immunohistochemical Analysis}

NF-E2-related factor 2 (Nfr2) and phospho-NF- $\kappa \mathrm{B}$ p65 expressions were examined by immunohistochemical analysis, respectively. The paraffin sections $(5 \mu \mathrm{m})$ were dewaxed and hydrated followed by antigen retrieval through heat mediation in Citrate Plus solution (ab94674, Abcam Trading (Shanghai) Company Ltd., Shanghai, China.) to recover protein structure. Then sections were rinsed with $3 \% \mathrm{H}_{2} \mathrm{O}_{2}$ and TBS buffer (50 mM Tris, $100 \mathrm{mM} \mathrm{NaCl}, \mathrm{pH}$ 7.6) to block endogenous peroxidase activity and excessive protein, and incubated with primary Nfr2 antibody or primary phospho-NF- $\kappa$ B antibody (AF0639 or AF2006, dilution 1:100, Affinity Biosciences, Cincinnati, USA) at $37^{\circ} \mathrm{C}$ for 30 minutes. After rinsing two times (5 minutes each time) with TBS buffer, sections were incubated with an horseradish peroxidase conjugated goat anti-rabbit antibody (dilution 1:100, S0001, Affinity Biosciences, Cincinnati, USA) for 30 minutes at $37^{\circ} \mathrm{C}$. Then, sections were washed using TBS buffer for 3 times with 5 minutes each, and incubated in diaminobenzidine (DAB) solution (ab127055, Abcam Trading (Shanghai) Company Ltd., Shanghai, China.), followed by counter-staining with $0.2 \%$ modified hematoxylin solution (Sigma-Aldrich Corp., St. Louis, MO, USA). The stained sections were examined under a LIRI-2006 microscope (Shanghai Optical Instrument Factory, Shanghai, China). The IHC analysis for Nrf2 and phospho-NF- $\mathrm{kB}$ p65 was evaluated according to the staining intensity of positive reaction and percentage of positive cells in a blind manner with a reported method ${ }^{30}$. The staining intensity was graded from 0 to 3 (score $=0$ : colorless, 
score $=1$ : pale-yellow, score $=2:$ brown-yellow, and score $=3:$ saddle-brown $).$ The score for the percentage of positive cells was graded from 0 to 4 (score $=0$ : negative, score $=1$ : fewer than $10 \%$ positive cells, score $=2: 10-50 \%$ positive cells, score $=3$ : $51-75 \%$ positive cells, and score $=4$ : over $75 \%$ positive cells). Representative five animals $(n=5)$ were analyze.

\section{Statistical Analysis.}

The results were presented as the means \pm S.E.M (standard error of mean). The data were statistically analyzed using one-way ANOVA for multiple group comparison followed by Newman-Keuls test using SPSS 19.0 statistical software (SPSS Inc., Chicago, IL, USA). $P \leq 0.05$ was considered statistically significant.

\section{- RESULTS}

\section{Changes in Body Weight, Food Intake, Liver Weight and Fat Weight.}

In the whole experimental period, the changes in the body weight of mouse in each group were expressed as the average daily body weight of mouse in each week. The body weight of mice both in the control group and the fructose group continued to gain from beginning to end (Figure 2A and Figure 2B). Compared with mice in the fructose group, the body weight were inhibited at dose of 0.5 and $1 \mathrm{~mL} / \mathrm{kg} \mathrm{BSSEE}$ and trends to decrease at dose of $2 \mathrm{~mL} / \mathrm{kg}$ of BSSEE after the BSSEE administration (Figure 2B). Before the BSSEE administration, the body weigh in mice received diet without fructose increased to $35.17 \mathrm{~g}$ from an initial weight of $16.7 \mathrm{~g}$, whereas the body weight in fructose-fed mice increased to 39.60 (Figure 2A) and showed significant difference compared to the control group. After oral administration of the 
BSSEE for consecutive 4 weeks, the body in fructose-fed mice slightly increased to $41.83 \mathrm{~g}$ from $39.67 \mathrm{~g}$ at the dose of $0.5 \mathrm{~mL} / \mathrm{kg}$ BSSEE and $40.17 \mathrm{~g}$ at the dose of 1 $\mathrm{mL} / \mathrm{kg}$ BSSEE from $39.17 \mathrm{~g}$ (Figure 2B), while oral administration of BSSEE at the dose of $2 \mathrm{~mL} / \mathrm{kg}$ slightly decreased body weight of mice to $38.00 \mathrm{~g}$ from the body weight of $40.09 \mathrm{~g}$ at the end of the $4 \mathrm{th}$ week (Figure 2B). However, mice received fructose without the BSSEE administration markedly increased to $45.83 \mathrm{~g}$ at the end of experiment (Figure 2B). The average body weight of mice treated with BSSEE $(0.5$, 1 and $2 \mathrm{~mL} / \mathrm{kg}$ ) significantly decreased compared with mice in the fructose group at the end of experiment, and significant difference was observed in mice administrated with BSSEE at 1 and $2 \mathrm{~mL} / \mathrm{kg}$ compared with the control group.

For the changes in the food intake, fructose-fed mice showed the decrease of food intake throughout the experiment, compared with the mice in the control group. We measured the average amount of food intake per day after the BSSEE treatment, in which the average amount of food intake in those fructose-fed mice administrated with BSSEE (1 and $2 \mathrm{~mL} / \mathrm{kg}$ ) showed significant reduction compared with mice in the fructose group (Table 2). Although energy intake in mice administrated with BSSEE at 1 and $2 \mathrm{~mL} / \mathrm{kg}$ showed less than mice in the fructose group, no significant difference were observed (Table 2).

At the end the of experiment, the liver weight, perinephrit fat weight, subcutaneous fat weight and epididymal fat weight in fructose group displayed significant increase compared to the control group, and the relative liver and total fat weights also significantly increased in fructose group (Table 1). Compared with mice 
in the fructose group, BSSEE treated mice showed the decrease in the liver weight, perinephrit fat weight, subcutaneous fat weight, epididymal fat weight, and the relative liver and total fat tissue weight in a dose dependent manner (Table 1).

\section{Effect of BSSEE on Serum Biochemical Parameters.}

At the end of the experiment, fructose-fed mice showed significant high levels of serum cholesterol, triglycerides, glucose, insulin and FFA levels (Table 2), which may imply that fructose feeding cause metabolic disorders. However, mice administrated with $\operatorname{BSSEE}(0.5,1$ or $2 \mathrm{~mL} / \mathrm{kg})$ significantly decreased serum cholesterol, triglycerides, glucose, insulin and FFA levels in a dose-dependent manner (Table 2).

Decreased these serum parameters by BSSEE indicated that BSSEE administration effectively improved metabolic disorders. In addition, AST and ALT levels in the fructose group are significant higher than that in the control group, whereas administration of BSSEE $(0.5,1$ and $2 \mathrm{~mL} / \mathrm{kg})$ dose-dependently reversed AST and ALT levels (Table 2). Furthermore, we determined the serum TNF- $\alpha$ and IL-6 levels in mice from all group because the increase of serum TNF- $\alpha$ and IL-6 levels is closely associated with the progression of liver fat deposition ${ }^{31}$. Notably, fructose fed-mice in the fructose group showed higher levels of TNF- $\alpha$ and IL- 6 than that in the control group. However, treatment with BSSEE (1 and $2 \mathrm{~mL} / \mathrm{kg}$ ) significantly reduced TNF- $\alpha$ and IL-6 in serum.

\section{Effect of BSSEE on Liver Inflammation Response and Histopathological}

\section{Changes.}

Triglycerides are the main lipids deposited in the liver of patients with NAFLD. 
352

353

354

We measured the hepatic triglycerides levels. Fructose administration significantly increased triglycerides level compared with mice in the control group, whereas mice administrated with BSSEE (1 and $2 \mathrm{~mL} / \mathrm{kg}$ ) significantly decreased hepatic triglycerides level (Figure.3E). Furthermore, the morphological changes of the hepatocytes of lobule were examined with $\mathrm{H} \& \mathrm{E}$ staining and oil red $\mathrm{O}$ staining, and the severity of histological changes was evaluated by the histopathological scoring system. Liver tissue stained with H\&E showed some marked changes in mice from the fructose group, where the hepatocytes of lobule in some sections showed ballooning degeneration (Figure.3F), and the ballooning degeneration score significantly increased compared with mice in the control group (Figure.3C). Meanwhile, liver tissue stained with oil red O showed fatty deposition of hepatocyte and high fatty deposition score in mice from the fructose group (Figure.3D). In contrast, $\mathrm{H} \& \mathrm{E}$ and oil red $\mathrm{O}$ staining displayed that the liver sections from fructose-fed mice treated with BSSEE (1 and $2 \mathrm{~mL} / \mathrm{kg}$ ) alleviated these histological alterations (Figure.3F) and significantly decreased the ballooning degeneration and fatty deposition scores (Figure.3C and Figure.3D) in a dose-dependent manner. Moreover, TNF- $\alpha$ (Figure.3A) and IL-6 (Figure.3B) are two important inflammatory cytokines, in which they drive the development of hepatic steatosis and inflammation in NAFLD. IL-6 and TNF- $\alpha$ levels in fructose-fed mice without the treatment significantly increased compared with mice in the control group, and there are some inflammatory cells infiltration in liver tissue sections stained with H\&E. Compared to mice in the fructose group, significant decrease in IL-6 and TNF- $\alpha$ levels with a 
dose-dependent manner was observed in mice administrated with $\operatorname{BSSEE}(0.5,1$ and $2 \mathrm{~mL} / \mathrm{kg}$ ), and no inflammatory cells infiltration were observed in liver tissue sections stained with H\&E in BSSEE $(0.5,1$ and $2 \mathrm{~mL} / \mathrm{kg})$ treated mice.

\section{BSSEE improved glucose homeostasis in fructose-fed mice}

To investigate the effect of BSSEE on body insulin sensitivity, mice were fasted and were intraperitoneally injected with either glucose (GTT) or insulin (ITT). As shown in Figure.4A, blood glucose level in fructose-fed mice without the treatment were constantly higher (statistically significant at 30 and 60 minutes) than mice in the control group mice, which was accompanied by higher levels of blood glucose level in ITT test at 60 and $90 \mathrm{~min}$ (Figure. 4C), suggesting that insulin sensitivity in fructose-fed mice without the treatment was relatively decreased. This notion was further strengthened by the analysis of AUC summarized in Figure.4B and Figure.4D, in which the area under the curve for the GTT and ITT in fructose group significantly increased to 29.19 and 9.24 compared with mice in the control group, respectively. However, administration with $\operatorname{BSSEE}(0.5,1$ and $2 \mathrm{~mL} / \mathrm{kg})$ lead to a significant decrease at $30 \mathrm{~min}$ for GTT (Figure. 4A) and at 60 and $90 \mathrm{~min}$ for ITT (Figure. 4C), and the total prevention of the increase in GTT area under the curve or ITT area under the curve was significantly decreased in a dose dependent manner (Figure. 4B and Figure. 4D), indicating that BSSEE treatment improved decreased insulin sensitivity in fructose-fed mice.

\section{Effect of BSSEE on Hepatic Oxidative Stress.}

SOD, CAT and GSH-Px are key antioxidant enzymes, which play important 
roles in maintaining the intracellular redox balance. Compared with mice in the control group, hepatic SOD (Figure.5E), CAT (Figure.5F) and GSH-Px (Figure.5G) activities decreased in fructose-fed mice without the treatment, but no significant difference was found in SOD and CAT compared with the control group. However, BSSEE administration at dose of $2 \mathrm{~mL} / \mathrm{kg}$ significantly increased hepatic SOD and CAT activities, and GSH-Px activities were also increased significantly in all BSSEE treated mice compared with the fructose group, indicating that BSSEE treatment enhanced hepatic antioxidant enzymes activities. In addition, vitamin C (Figure.5D) and GSH (Figure.5C) is known to be important antioxidants to scavenging free radicals in different tissues, whereas NO (Figure.5B) and MDA (Figure.5A) are indicators of oxidative stress. Mice in the fructose group showed significant low levels of hepatic vitamin $\mathrm{C}$ and GSH, and high levels of NO and MDA, compared to the control group. In contrast, $\operatorname{BSSEE}(0.5,1$ and $2 \mathrm{~mL} / \mathrm{kg})$ treatment increased hepatic vitamin $\mathrm{C}$ and GSH levels, and a significant difference showed in BSSEE 2 $\mathrm{mL} / \mathrm{kg}$ treated mice. Meanwhile, all BSSEE treated groups showed low level of MDA, and hepatic NO level decreased in BSSEE 1 and $2 \mathrm{~mL} / \mathrm{kg}$ treated mice compared with mice in the fructose group. All of these results suggested that BSSEE administration decreased hepatic oxidative stress.

In order to explore whether BSSEE can improve hepatic oxidative stress, immunohistochemical staining of Nrf2 expression was carried out. Nrf2 is a transcription factor in the protection against any oxidative stress, which is translocated from sequestration in thecytoplasm to the nucleus during oxidative stress, promoting 
several antioxidant enzymes to enhance antioxidant defense system. Nrf2 are low expressed in liver cell of nuclear in mice form the fructose group, whereas mice treatment with BSSEE at doses of 1 and $2 \mathrm{~mL} / \mathrm{kg}$ elevated $\mathrm{Nrf} 2$ expression in cells of nuclear, suggesting that the anti-oxidant effect of BSSEE linked with increase of Nrf2 expression in cells of nuclear (Figure.5H and Figure.5H).

\section{Effect of BSSEE on Liver Protein Expression.}

Insulin resistance is a risk factor for the aggravation of NAFLD, in which inflammatory mediators and lipids activate a signaling cascade that triggers inflammatory kinases such as JNK, IKK and NF- $\kappa \mathrm{B}$, as well as XBP1. The activation of JNK, IKK and NF- $\kappa \mathrm{B}$ and down-regulation of XBP1 can result in the inhibition of insulin action in part through serine phosphorylation of insulin receptor substrates IRS1. In the present study, fructose-fed mice showed the high expressions of phospho-JNK1 (Figure.6C) and phospho-IKK (Figure.6B), along with low expressions of XBP1 (Figure.6A) and phospho-IRS1 (Figure.6D), compared with mice in the control group. In addition, immunohistochemical staining of phospho-NF- $\kappa$ B p65 expression obviously increased in the fructose-fed mice without the treatment (Figure.6E). However, mice treated with BSSEE decreased expressions of phospho-NF-kB p65, phospho-JNK1, phospho-IRS1 and phospho-IKK, and increased expression of XBP1 (Figure.6A-E), indicating that BSSEE administration markedly improved insulin resistance in liver of mice by its effect on these signalling molecules.

\section{- DISCUSSION}


Long term intake of high fructose has been proven to be a risk factor for the development of obesity, adiposity, liver inflammation and insulin resistance, as well as NAFLD, insulin resistance and metabolic syndrome ${ }^{5-10}$. Since HFCS consumption has been found that it is closely associated with the increasing prevalence of NAFLD, obesity, insulin resistance and metabolic syndrome, we investigated the effect of BSSEE on NAFLD in fructose-fed mice. In this study, $30 \%$ of fructose intake over a period of 8 weeks caused fast body weight gain together with increase of fat tissue and liver weights in mice, which is similar to previous report ${ }^{10}$. Overweight that presents an increase of lipids in adipose tissue is considered to be one of the key events occurring in the first steps of hepatic steatosis, where adipose tissue-derived signals (e.g. classical cytokines TNF- $\alpha$, IL-6) due to excess storage of fat has been demonstrated to play an essential role in the pathopoiesia of NAFLD ${ }^{3,31}$. However, BSSEE intake decreased body weight, adipose tissue weight and liver weight, implying that BSSEE may contribute to the improvement of NAFLD in fructose-fed mice. Importantly, in addition to the improvement of serum biochemical parameters levels after BSSEE intake in fructose-fed mice, further histopathological examinations showed that BSSEE supplementation reduced ballooning degeneration and fat deposition in liver cells compared with the fructose-fed mice without the treatment. Certainly, our experimental results indicate that BSSEE intake could alleviate hepatic steatosis in fructose-fed mice.

In the present study, the major active components of BSSEE were analyzed with HPLC-PDA. On the basis of the BSSEE chromatogram (Figure 1), the results 
indicated that the major constituent of BSSEE was lignans (19.8\%), which mainly contained sesaminol (1.92\%), sesamin (16.33\%) and sesamolin (31.31\%). Previously, vitamins (such as vitamins D, vitamins $\mathrm{C}$ and vitamins E) ${ }^{32,33}$ and linoleic acids ${ }^{34}$ were found to be beneficial for the improvement of NAFLD. In the present study, sugar, protein, vitamins and fatty acids in BSSEE were did not detected under that chromatographic conditions. Since soybean oil mainly contain linoleic acid (55\% 67\%), oleic acid (17\% 26\%), palmitic acid (9\% 13\%), stearic acid (3\% 6\%) as well as vitamins, mice in the fructose group received soybean oil showed no significant improvement in fructose-induced NAFLD. Therefore, lignans including sesaminol (1.92\%), sesamin (16.33\%) and sesamolin (13.06\%) might possess beneficial effect against NAFLD in this animal model.

In the present study, fructose consumption increased serum levels of FFA, triglyceride and total cholesterol. Disorganized these serum parameters altered change in energy metabolism in liver, and are risk factors in the development of diseases such as NAFLD, insulin resistance and metabolic syndrome. Increased free fatty acids, triglyceride and cholesterol, especially accumulation in mitochondria, are considered the "aggressive" lipids leading to TNF- $\alpha$ and IL-6-mediated liver damage and ROS formation ${ }^{31,35}$. These lipids could also shows in a nonsteatotic liver and act as early "inflammatory" hits, resulting in the whole spectrum of NAFLD pathologies ${ }^{36,37}$. However, we observed BSSEE supplementation decreased free fatty acid, triglyceride and total cholesterol, which is beneficial to the prevention in the development of NAFLD. 

presented the increase of serum insulin and glucose levels, and ITT and GTT tests. Insulin resistance is the condition that a cell, tissue, or organism fails to respond appropriately to a given dose of insulin, in which it is an important feature of NAFLD and type 2 diabetes, and are often found in metabolic syndrome ${ }^{38}$. The improvement of NAFLD may occur independent of interference with insulin resistance 39,40 . However, presence of insulin resistance may aggravate NAFLD because patients with insulin resistance are often worse in terms of liver histopathological examinations such as hepatic ballooning, steatosis and degree of fibrosis ${ }^{41,42}$. In contrast, oral administration of BSSEE $(0.5,1$ and $2 \mathrm{mg} / \mathrm{kg})$ dose-dependently decreased serum insulin and glucose levels and improved body insulin resistance, which is important for the prevention of NAFLD complicated with type 2 diabetes and metabolic syndrome.

In addition to plasma insulin resistance, we found that fructose intake over a long IRS1 (Ser 307) may prevent insulin signal transduction, thereby resulting in

501 impairment of insulin functions in liver ${ }^{4}$. Impaired hepatic insulin function is linked 502 with the exacerbation of NAFLD ${ }^{43}$. Mice treated with BSSEE improved insulin 503 function, showing decreased serine phosphorylation of IRS1 (Ser 307), which was contribute to the metabolism of glucose and lipid in liver. In order to further 
hepatic oxidative stress and the expressions of NF- $\mathrm{BB}$, JNK1, IKK and XBP1 in liver. One of the key aspects that disrupt insulin signaling links to major inflammatory signaling networks, including the activation of the JNK, IKK/NF- $\kappa \mathrm{B}$ signaling pathways and production of ROS and NO ${ }^{44}$. The activation of JNK, IKK-NF- $\mathrm{BB}$ pathways can lead to the inhibition of insulin action in part through serine phosphorylation of IRS1 45, 46. However, mice by BSSEE treatment reduced phosphorylation of NF- $\mathrm{KB}$ p65, JNK1 and IKK, and consequently a decrease of serine phosphorylated IRS1 (Ser 307), suggesting that BSSEE could improve insulin signal transduction via its effect on JNK and IKK-NF-אB pathways. In addition, XBP1 has evolved as a critical molecule, which interacts with inflammatory cascades at various stages, including IRE1-mediated activation of JNK, activation of IKK/NF- $\kappa \mathrm{B}$ signaling pathways and production of $\mathrm{ROS}^{44}$. XBP1 haploinsufficiency in mice exhibit markedly increased succumb to increase of body weight, hyperinsulinemia, hyperglycemia, and impaired glucose and insulin tolerance, at least in part, through activation of JNK and serine phosphorylation of IRS1 47,48 . XBP1 has proved as a critical molecule in the regulation all aspects of NAFLD ${ }^{49}$. Notably, BSSEE increased expression of XBP1 in liver compared with mice in fructose group, which may be, in part, responsible for the regulation of the lipid synthesis/accumulation, inflammation and insulin signaling/resistance in liver in fructose-fed mice.

As above mentioned, production of ROS and NO has been considered as strong contenders for the cause of exacerbating NAFLD and insulin resistance ${ }^{11}$. The liver is rich in antioxidant defense system, which include chemicals such as GSH, vitamins C, 
and enzymes such as SOD, CAT, GSH-px ${ }^{50}$. Even though ROS and nitrogen species are normally produced by the metabolism of normal cells, in NAFLD the occurrence that an overproduction of free radicals which overcomes the antioxidant defenses aggravate liver injury ${ }^{51}$. The pathogenesis of NAFLD suffers multiple parallel hits, including oxidative stress ${ }^{31,52}$. Hepatic oxidative stress is also partly responsible for insulin resistance through inflammatory response ${ }^{53}$. In the present study, fructose-fed mice showed decrease of GSH and vitamins C levels, reductions of SOD, CAT and GSH-px activities, and high levels of MDA and NO in liver, suggesting decrease of antioxidant defenses function. However, BSSEE enhances antioxidant defenses function, as increase of GSH and vitamins C levels, enhancements of SOD, CAT and GSH-px activities and consequently reduction of MDA and NO level. To understand thoroughly the molecular mechanism behind the antioxidative effect of BSSEE, we further examined hepatic Nrf2 protein. Nrf2 is a transcription factor binds antioxidant response elements (AREs) in the regulatory regions of target genes, which act as a main player in the inducible expression of our cellular defense enzymes ${ }^{54,55}$. Nrf2 activators have already been developed for the treatment of liver diseases involving oxidative stress and inflammatory response ${ }^{56,57}$. Similar to previous studies, the present study found that BSSEE could increased Nrf2 expression in liver cell, which might have a significant protective effect against fructose-induced oxidative stress in liver as can be seen in this study, possibly through enhancing hepatic antioxidant defense enzymes.

In conclusion, the present study demonstrates for the first time that BSSEE 
550

551

552

553

554

555

556

557

558

559

560

561

562

563

564

565

566

567

568

569

570

571

showed good beneficial effects against NAFLD complicated with insulin resistance and metabolic syndrome in fructose-fed mice. These effects are most likely related to the regulation of insulin signaling molecules expressions, antioxidant defenses system and inflammatory response. Thus, black sesame seeds could be considered as a potent dietary supplements in the prevention of NAFLD-related metabolic diseases.

- AUTHOR INFORMATION

\section{Corresponding Author}

*(Yongmin Zhang) Postal address: Sorbonne Université, Institut Parisien de Chimie Moléculaire, CNRS UMR 8232, 4 place Jussieu, 75005 Paris, France. Tel: +86 29 88304569. Fax: +86 29 88304368. E-mail: 15102930802@163.com.

\section{Funding}

This work was financially supported by the Natural Science Foundation of Shaanxi Province of China, One Hundred Person Expert Project of Shaanxi Province of China (No. 2014JM4125), Special research program of Shaanxi Provincial Department of Education (No. 2013JK0809).

\section{Notes}

The authors declare no competing financial interest.

\section{- ABBREVIATIONS USED}

Black sesame seeds ethanol extract (BSSEE), nonalcoholic fatty liver disease (NAFLD), free fatty acids (FFA), aspartate transaminase (AST), alanine transaminase (ALT), insulin tolerance tests (ITT), glucose tolerance tests (GTT), nitric oxide (NO), malondialdehyde (MDA), NF-E2-related factor 2 (Nrf2), superoxide dismutase (SOD), 
572 catalase (CAT), glutathione peroxidase (GSH-Px), phospho-c-Jun NH2-terminal

573 kinase 1 (phospho-JNK1), phospho-nuclear factor kappa B (NF-kB), phospho-insulin

574 receptor substrate 1 (phospho-IRS1), phospho-IкB kinase (phospho-IKK), X-box

575 binding protein 1 (XBP1), tumor necrosis factor alpha (TNF- $\alpha$ ), interleukin-6 (IL-6),

576 reactive oxygen species (ROS), high performance liquid chromatography (HPLC),

577 high fructose corn syrup (HFCS).

578

579

580

581

582

583

584

585

586

587

588

589

590

591

592

593 
595 1. Glen J.; Floros L.; Day C.; Pryke R. Non-alcoholic fatty liver disease (NAFLD): 596 summary of NICE guidance. Br. Med. J. 2016, 354, i4428.

2. Do A.; Lim J.K. Epidemiology of nonalcoholic fatty liver disease: a primer. Clin.

598

599

600

601

602

603

604

605

606

607

608

609

610

611

612

613

614

615
Liver Dis. 2016, 7, 106-108.

3. Al-Dayyat H.M.; Rayyan Y.M.; Tayyem R.F. Non-alcoholic fatty liver disease and associated dietary and lifestyle risk factors. Diabetes \& Metabolic Syndrome: Clinical Research \& Reviews. 2018, https://doi.org/10.1016/j.dsx.2018.03.016.

4. Hotamisligil G.S. Endoplasmic reticulum stress and the inflammatory basis of metabolic disease. Cell. 2010, 6, 900-917.

5. Spruss A.; Bergheim I. Dietary fructose and intestinal barrier: potential risk factor in the pathogenesis of nonalcoholic fatty liver disease. J. Nutr. Biochem. 2009, 20, 657-662.

6. Castello A.; Guma A.; Sevilla L.; et al. Regulation of GLUT5 gene expression in rat intestinal mucosa: regional distribution, circadian rhythm, perinatal development and effect of diabetes. Biochem. J. 1995, 309 (Pt 1), 271-277.

7. Nomura K.; Yamanouchi T. The role of fructose-enriched diets in mechanisms of nonalcoholic fatty liver disease. J. Nutr. Biochem. 2012, 23, 203-208.

8. Suganthi R.; Rajamani S.; Ravichandran M.K.; Anuradha C.V. Effect of food seasoning spices mixture on biomarkers of oxidative stress in tissues of fructose-fed insulin-resistant rats. J. Med. Food. 2007, 10, 149-153.

9. Armutcu F.; Coskun O.; Gurel A.; et al. Thymosin alpha 1 attenuates lipid 
616

617

618

619

620

621

622

623

624

625

626

627

628

629

630

631

632

633

634

635

636

637

peroxidation and improves fructose-induced steatohepatitis in rats. Clin. Biochem. $2005,38,540-547$.

10. Bagul P.K.; Middela H.; Matapally S.; Padiya R.; Bastia T. Attenuation of insulin resistance, metabolic syndrome and hepatic oxidative stress by resveratrol in fructose-fed rats. Pharmacol. Res. 2012, 66, 260-268.

11. Gaetano S.; Francesco B.; Gianluigi V. Free radical biology for medicine: learning from nonalcoholic fatty liver disease. Free Radical Biol. Med. 2013, 65, 952-968.

12. Raghav R.; David C. Sesame: New Approaches for Crop Improvement. Juan Romero \& Craig Cowley. 1990. Purdue University.

13. BBC. FOOD INGREDIENTS. Black sesame seeds recipes. URL (https://www.bbc.com/food/black_sesame_seeds).

14. Chinese Herbs Healing. Black Sesame Seeds (Semen Sesami Nigrum, Hei Zhi Ma). URL (http://www.chineseherbshealing.com/black-sesame-seeds/).

15. Zhou L.; Lin X.; Mehmood A.A.; Zheng B. Phytochemical Contents and Antioxidant and Antiproliferative Activities of Selected Black and White Sesame Seeds. Biomed. Res. Int. 2016, 2016, 8495630.

16. Hu Q.; Xu J.; Chen S.; Yang F. Antioxidant activity of extracts of black sesame seed (Sesamum indicum L.) by supercritical carbon dioxide extraction. J. Agric. Food Chem. 2004, 52, 943-947.

17. Shahidi F.; Liyana-Pathirana C.M.; Wall D.S. Antioxidant activity of white and black sesame seeds and their hull fractions. Food Chem. 2006, 99, 478-483.

18. Periasamy S.; Chien S.P.; Chang P.C.; Hsu D.Z.; Liu M.Y. Sesame oil mitigates 
638

639

640

641

642

643

644

645

646

647

648

649

650

651

652

653

654

655

656

657

658

659

nutritional steatohepatitis via attenuation of oxidative stress and inflammation: a tale of two-hit hypothesis. J. Nutr. Biochem. 2014, 25, 232-240.

19. Periasamy S.; Hsu D.Z.; Chien S.P.; Chang P.C.; Liu M.Y. A single dose of sesame oil alleviates liver injury and steatosis in steatohepatitis via modulation of oxidative stress, cytokines and PPAR-I(lalphal). Curr. Diabetes Rep. 2015, 13, 261-70.

20. Zhang R.; Yu Y.; Hu S.; Zhang J.; Yang H.; et al. Sesamin ameliorates hepatic steatosis and inflammation in rats on a high-fat diet via LXR $\alpha$ and PPAR $\alpha$. Nutr. Res. 2016, 36, 1022-1030.

21. Liu C.M.; Zheng G.H.; Ming Q.L.; Chao C.; Sun J.M. Sesamin Protects Mouse Liver against Nickel-Induced Oxidative DNA Damage and Apoptosis by the PI3K-Akt Pathway. J. Agric. Food Chem. 2013, 61, 1146-54.

22. Sirato-Yasumoto S.; Katsuta M.; Okuyama Y.; Takahashi Y.; Ide T. Effect of sesame seeds rich in sesamin and sesamolin on fatty acid oxidation in rat liver. J. Agric. Food Chem. 2001, 49, 2647-51.

23. Kang M.H.; Naito M.; Tsujihara N.; Osawa T. Sesamolin inhibits lipid peroxidation in rat liver and kidney. J. Nutr. 1998, 128, 1018.

24. Liu Z.; Qiao Q.; Sun Y.; Chen Y.; Ren B.; et al. Sesamol ameliorates diet-induced obesity in C57BL/6J mice and suppresses adipogenesis in 3T3-L1 cells via regulating mitochondria-lipid metabolism. Mol. Nutr. Food Res. 2017, 61.

25. Singh N.; Khullar N.; Kakkar V.; Kaur I.P. Hepatoprotective effects of sesamol loaded solid lipid nanoparticles in carbon tetrachloride induced sub- chronic hepatotoxicity in rats. Environ. Toxicol. 2016, 31, 520-532. 
26. Noh Ryu S.U.; Chi-Tang H.O.; Osawa T. HIGH PERFORMANCE LIQUID CHROMATOGRAPHIC DETERMINATION OF ANTIOXIDANT LIGNAN GLYCOSIDES IN SOME VARIETIES OF SESAME. J. Food Lipids. 2010, 5, 17-28.

27. Liang W.; Menke A.L.; Driessen A.; Koek G.H.; Lindeman J.H.; et al. Establishment of a general NAFLD scoring system for rodent models and comparison to human liver pathology. PLoS One. 2014, 9, e115922.

28. Matthews J.N.; Altman D.G.; Campbell M.J.; et al. Analysis of serial measurements in medical research. BMJ [Br. Med. J.], 1990, 300, 230-235.

29. Fossati P.; Prencipe L. Serum glycerides determined colourimetrically with an enzyme that produces hydrogen peroxide. Clin. Chem. 1982, 28, 2077-2080.

30. Zhu L., Xu H., Lv W., He Z., Ye P., 2018. miR-199b-5p Regulates Immune-Mediated Allograft Rejection after Lung Transplantation Through the GSK3 $\beta$ and NF- $\kappa B$ Pathways. Inflammation. 41, 1524-1535.

31. Herbert T.; Alexander R.M. Evolution of inflammation in nonalcoholic fatty liver disease: the multiple parallel hits hypothesis. Hepatology. 2010, 52, 1836-1846.

32. Eliades M.; Spyrou E.; Agrawal N.; Lazo M.; Brancati F.L. Meta-analysis: vitamin D and non-alcoholic fatty liver disease. Aliment. Pharmacol. Ther. 2013, 38, 246-254.

33. Oliveira C.P.; Gayotto L.C.; Tatai C.; Della Nina B.I.; Lima E.S. Vitamin C and Vitamin E in Prevention of Nonalcoholic Fatty Liver Disease (NAFLD) in Choline Deficient Diet Fed Rats. Nutrition Journal, 2003, 2 (1), 9-9.

34. Monteiro J.; Askarian F.; Nakamura M.T.; Moghadasian M.H.; Ma D.W. Oils rich 
682

683

684

685

686

687

688

689

690

691

692

693

694

695

696

697

698

699

700

701

702

703

in $\alpha$-linolenic acid independently protect against characteristics of fatty liver disease in the $\Delta 6$-desaturase null mouse. Can. J. Physiol. Pharmacol. 2013, 91 (6) :469-479.

35. Feldstein A.E.; Werneburg N.W.; Canbay A.; Guicciardi M.E.; Bronk S.F.; Rydzewski R.; et al. Free fatty acids promote hepatic lipotoxicity by stimulating TNF-alpha expression via a lysosomal pathway. Hepatology. 2004, 40, 185-194.

36. Malhi H.; Gores G.J. Molecular mechanisms of lipotoxicity in nonalcoholic fatty liver disease. Sem. in Liver Dis. 2008, 28, 360-369.

37. Alkhouri N.; Dixon L.J.; Feldstein A.E. Lipotoxicity in nonalcoholic fatty liver disease: not all lipids are created equal. Expert. Rev. Gastroenterol. Hepatol. 2009, 3, $445-451$.

38. Asrih M.; Jornayvaz F.R. Metabolic syndrome and nonalcoholic fatty liver disease: Is insulin resistance the link?. Mol. Cell. Endocrinol. 2015, 418, 55-65.

39. Amaro A.; Fabbrini E.; Kars M.; Yue P.; Schechtman K.; Schonfeld G.; et al. Dissociation between intrahepatic triglyceride content and insulin resistance in familial hypobetalipoproteinemia. Gastroenterology. 2010, 139, 149-153.

40. Sanyal A.J.; Chalasani N.; Kowdley K.V.; McCullough A.; Diehl A.M.; Bass N.M.; et al. Pioglitazone, vitamin E, or placebo for nonalcoholic steatohepatitis. N. Engl. J. Med. 2010, 362, 1675-1685.

41. Eguchi, Y.; Eguchi, T.; Mizuta, T.; Ide, Y.; Yasutake, T.; Iwakiri, R.; et al. Visceral fat accumulation and insulin resistance are important factors in nonalcoholic fattyliver disease. J. Gastroenterol. 2006, 41, 462-469.

42. Ota T.; Takamura T.; Kurita S.; Matsuzawa N.; Kita Y., Uno M.; et al. Insulin 
resistance accelerates a dietary rat model of nonalcoholic steatohepatitis. Gastroenterology. 2007, 132, 282-293.

43. Sabio G.; Das M.; Mora A.; Zhang Z.; Jun J.Y.; et al. A stress signaling pathway in adipose tissue regulates hepatic insulin resistance. Science. 2008, 322, 1539-1543.

44. Hotamisligil G.S. Endoplasmic Reticulum Stress and the Inflammatory Basis of Metabolic Disease. Cell. 2010, 140, 900-917.

45. Cai D.; Yuan M.; Frantz D.F.; Melendez P.A.; Hansen L.; Lee J.; et al. Local and systemic insulin resistance resulting from hepatic activation of IKK-beta and NF-kappaB. Nat. Med. 2005, 11, 183-190.

46. Arkan M.C.; Hevener A.L.; Greten F.R.; Maeda S.; Li Z.W.; Long J.M.; et al. IKK-beta links inflammation to obesity-induced insulin resistance. Nat. Med. 2005, 11, 191-198.

47. Park S.W.; Zhou Y.; Lee J.; Lu A.; Sun C.; Chung J.; et al. The regulatory subunits of PI3K, p85alpha and p85beta, interact with XBP-1 and increase its nuclear translocation. Nat. Med. 2010, 16, 429-437.

48. Winnay J.N.; Boucher J.; Mori M.A.; Ueki K.; Kahn C.R. A regulatory subunit of phosphoinositide 3-kinase increases the nuclear accumulation of X-box-binding protein-1 to modulate the unfolded protein response. Nat. Med. 2010, 16, 438-445.

49. Ozcan L.; Ergin A.S.; Lu A.; Chung J.; Sarkar S.; Nie D.; et al. Endoplasmic reticulum stress plays a central role in development of leptin resistance. Cell Metab. $2009,9,35-51$.

50. Leclercq I.A. Antioxidant defence mechanisms: new players in the pathogenesis 
of nonalcoholic steatohepatitis? Clin. Sci. 2004, 106, 235-237.

51. Muriel P. Role of free radicals in liver diseases. Hepatol. Int. 2009, 3, 526-536.

52. Day C.P.; James O.F. Steatohepatitis: a tale of two "hits"? Gastroenterology. 1998, $114,842-845$.

53. Houstis N.; Rosen E.D.; Lander E.S. Reactive oxygen species have a causal role in multiple forms of insulin resistance. Nature. 2006, 440, 944-948.

54. Itoh K.; Chiba T.; Takahashi S.; Ishii T.; Igarashi K.; et al. An Nrf2/small Maf heterodimer mediates the induction of phase II detoxifying enzyme genes through antioxidant response elements. Biochem. Biophys. Res. Commun. 1997, 236, 313-322.

55. Itoh K.; Wakabayashi N.; Katoh Y.; Ishii T.; Igarashi K.; et al. Keap1 represses nuclear activation of antioxidant responsive elements by Nrf2 through binding to the amino-terminal Neh2 domain. Genes Dev., 1999, 13, 76-86.

56. Bellezza I.; Giambanco I.; Minelli A.; Donato R. Nrf2-Keap1 signaling in oxidative and reductive stress. Biochim. Biophys. Acta. 2018, 1865, 721-733.

57. Yu Z.; Shao W.; Chiang Y.; Foltz W.; Zhang Z.; Ling W.; et al. Oltipraz upregulates the nuclear factor (erythroid-derived 2)-like 2 (NRF2) antioxidant system and prevents insulin resistance and obesity induced by a high-fat diet in C57BL/6J mice. Diabetologia. 2011, 54, 922-34. 


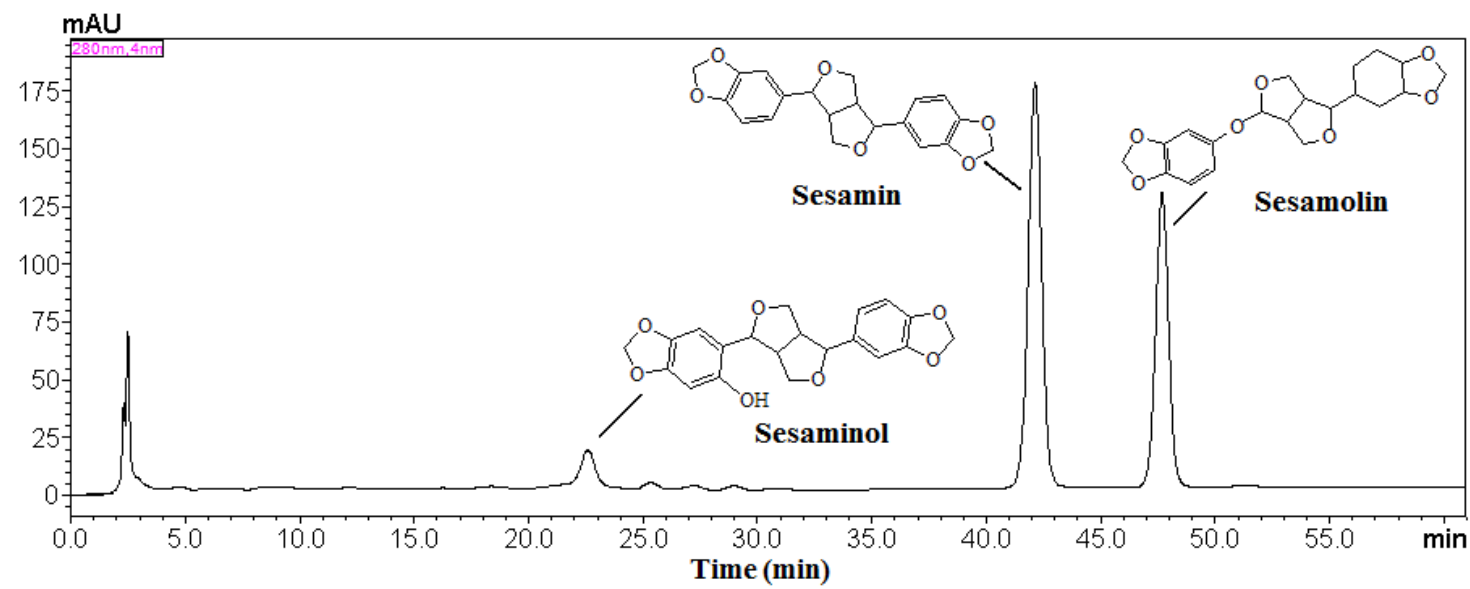

747

Figure 1. HPLC-PDA chromatogram of black sesame seeds ethanol extract (BSSEE) at $280 \mathrm{~nm}$. Retention times

and chemical structures of the three major components present in BSSEE are shown.

750

751

752

753

754

755

756

757

758

759

760

761

762

763 
765

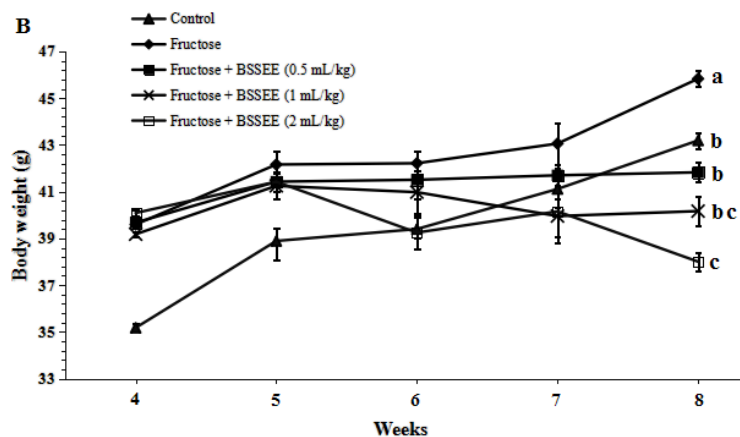

Figure.2. Changes in body weight and amount of food intake. (A) Curve showing changes in average body weight

between the control group and the fructose-fed group before BSSEE $(0.5,1$ and $2 \mathrm{~mL} / \mathrm{kg})$ treatment, in which fructose feeding obviously increased body weight compared with mice in the control group. (B) Curve showing changes in body weight from all group after $\operatorname{BSSEE}(0.5,1$ and $2 \mathrm{~mL} / \mathrm{kg})$ treatment, indicating that BSSEE treatment significantly reduced body weight at the end of the experiment, compared with mice in the fructose group. Values are expressed as means \pm SEM ( $n=10$ per group). Results were statistically analyzed using one-way ANOVA coupled with Newman-Keuls's multiple-comparison test $(p<0.05)$. 

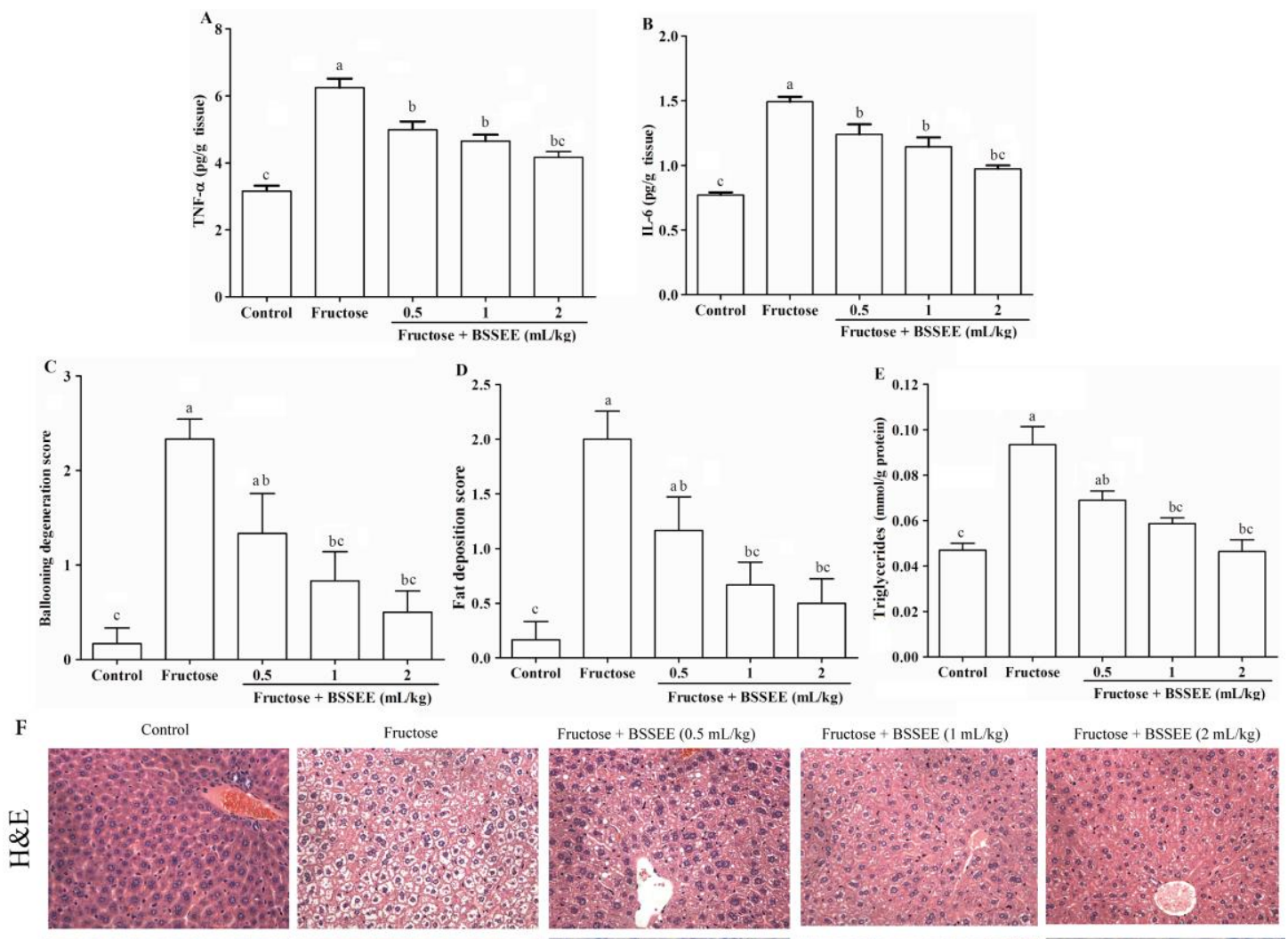

Fructose + BSSEE $(2 \mathrm{~mL} / \mathrm{kg})$
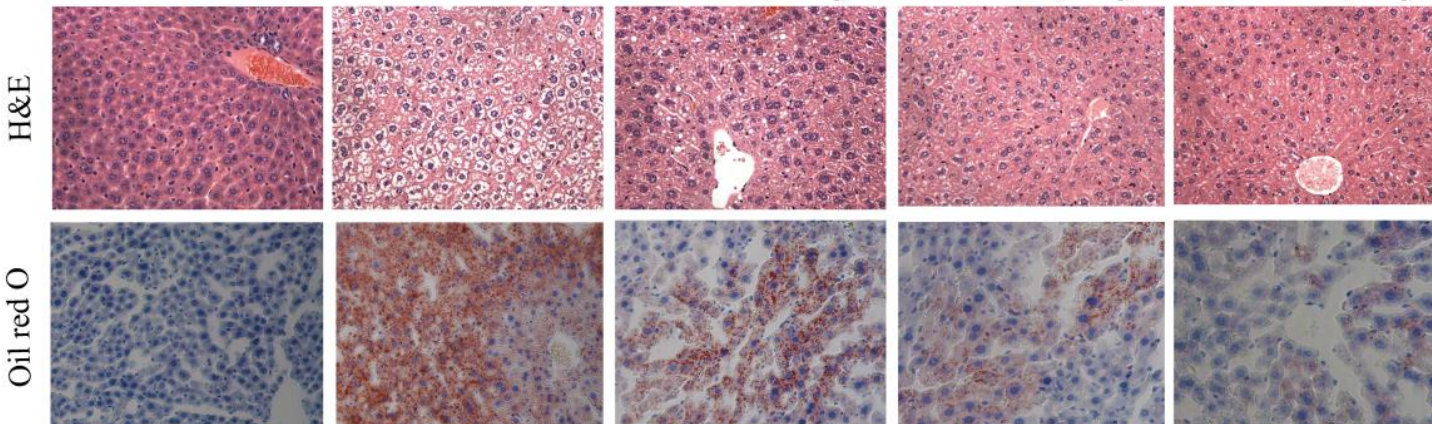

Figure.3. Effects of BSSEE (0.5, 1 and $2 \mathrm{~mL} / \mathrm{kg}$ ) on hepatic (A) TNF- $\alpha$, (B) IL-6 and liver histopathological

triglycerides. (F) Liver tissue stained with $\mathrm{H} \& \mathrm{E}(\times 400$ magnification) and oil red $\mathrm{O}(\times 800$ magnification) show 

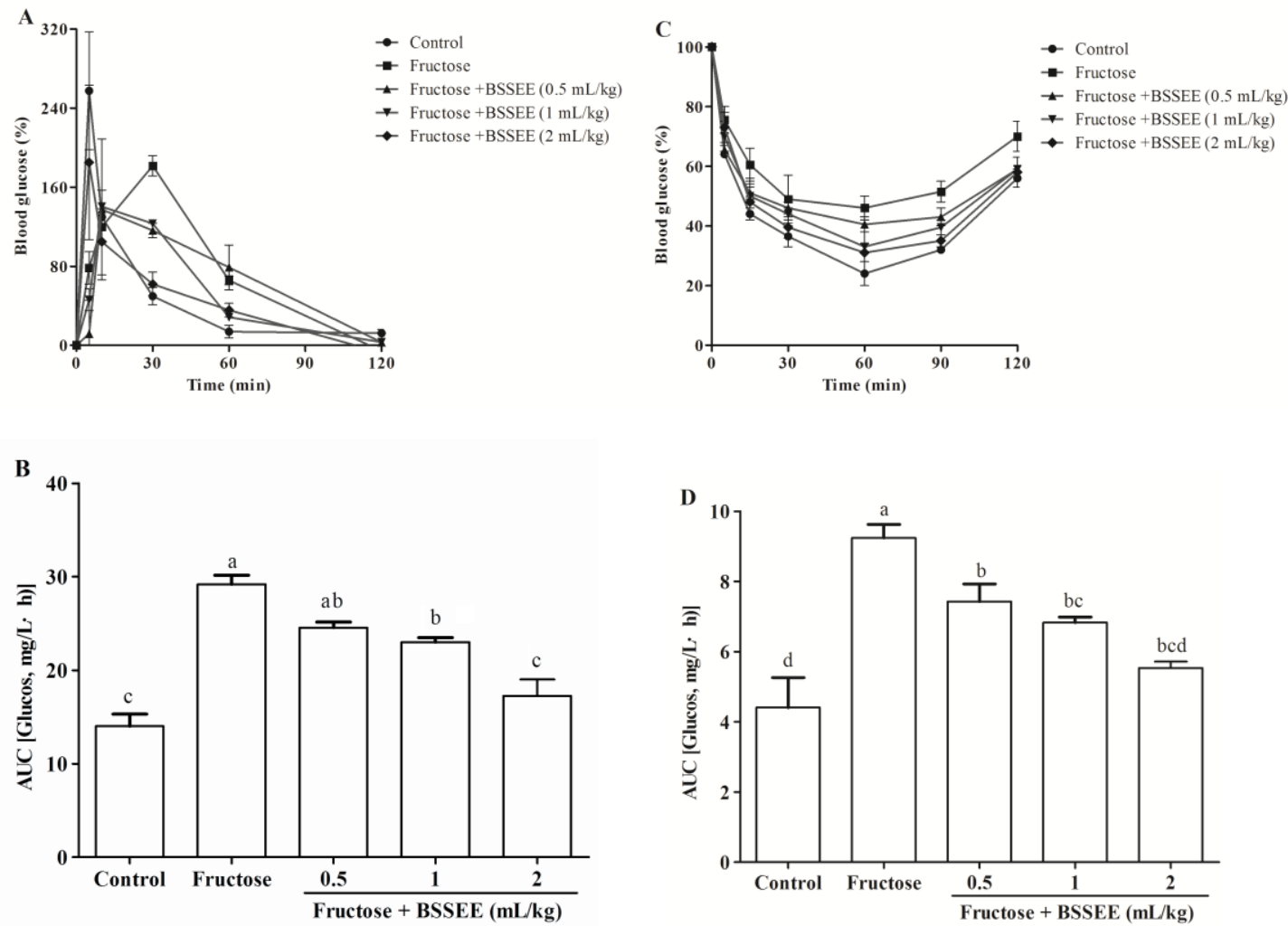

Fig. 4. Effects of BSSEE (0.5, 1 and $2 \mathrm{~mL} / \mathrm{kg})$ on GTT and ITT responses in fructose-fed mice. GTT (A) and ITT 

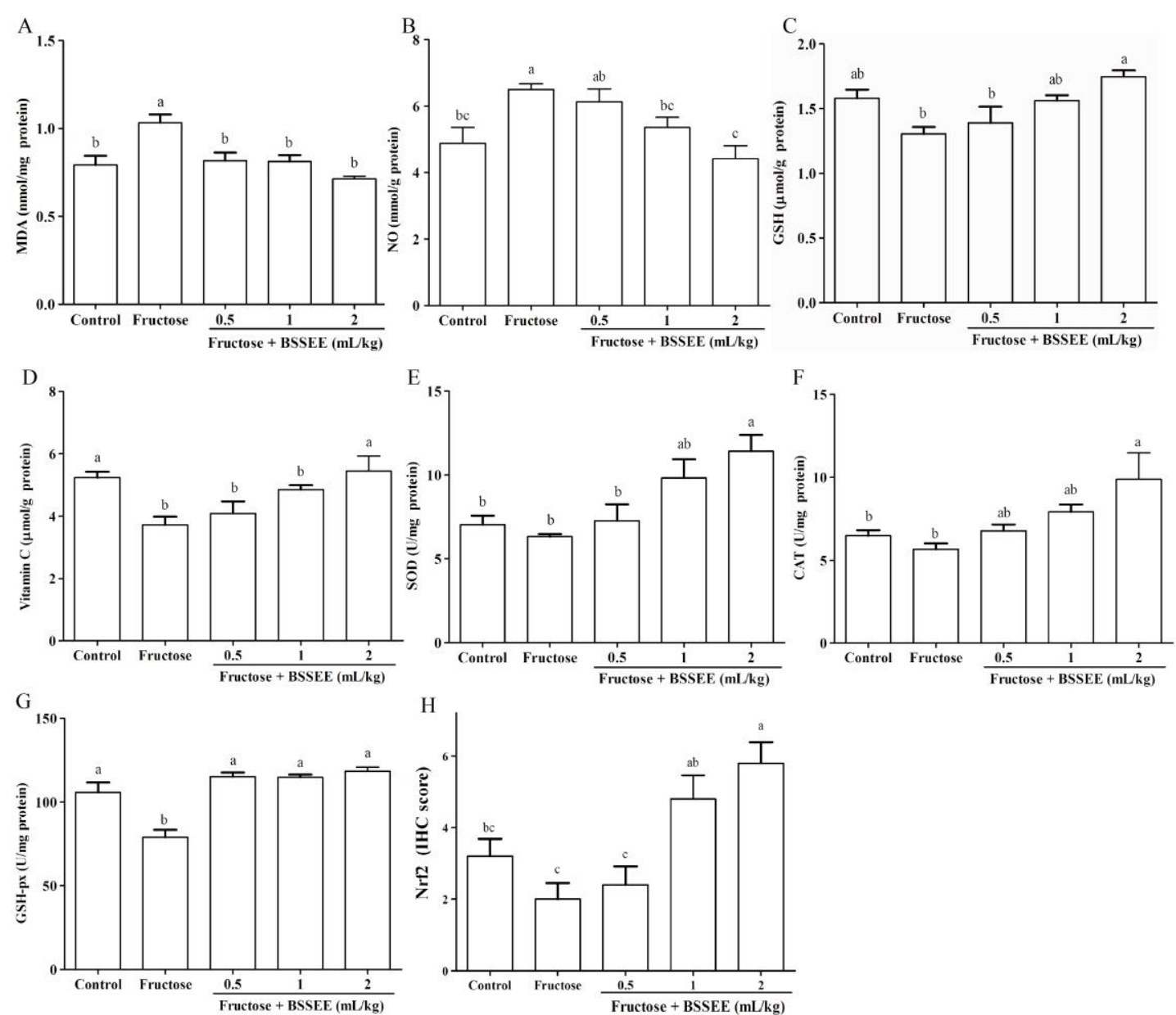

I
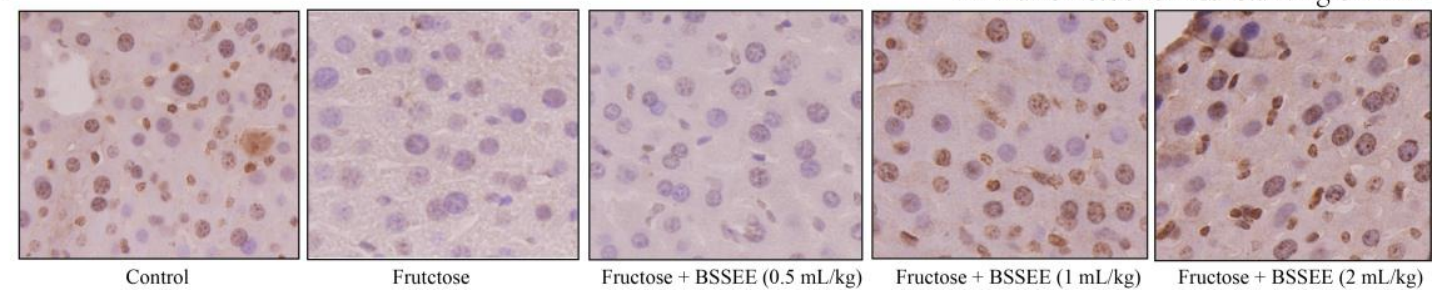

Figure.5. Effects of BSSEE (0.5, 1 and $2 \mathrm{~mL} / \mathrm{kg}$ ) on (A)MDA, (B) NO, (C) GSH, (D) vitamin C, (E) SOD, (F)

CAT and (G) GSH-Px. (H and I) The expression of Nfr2 is analyzed by immunohistochemistry (IHC) and 

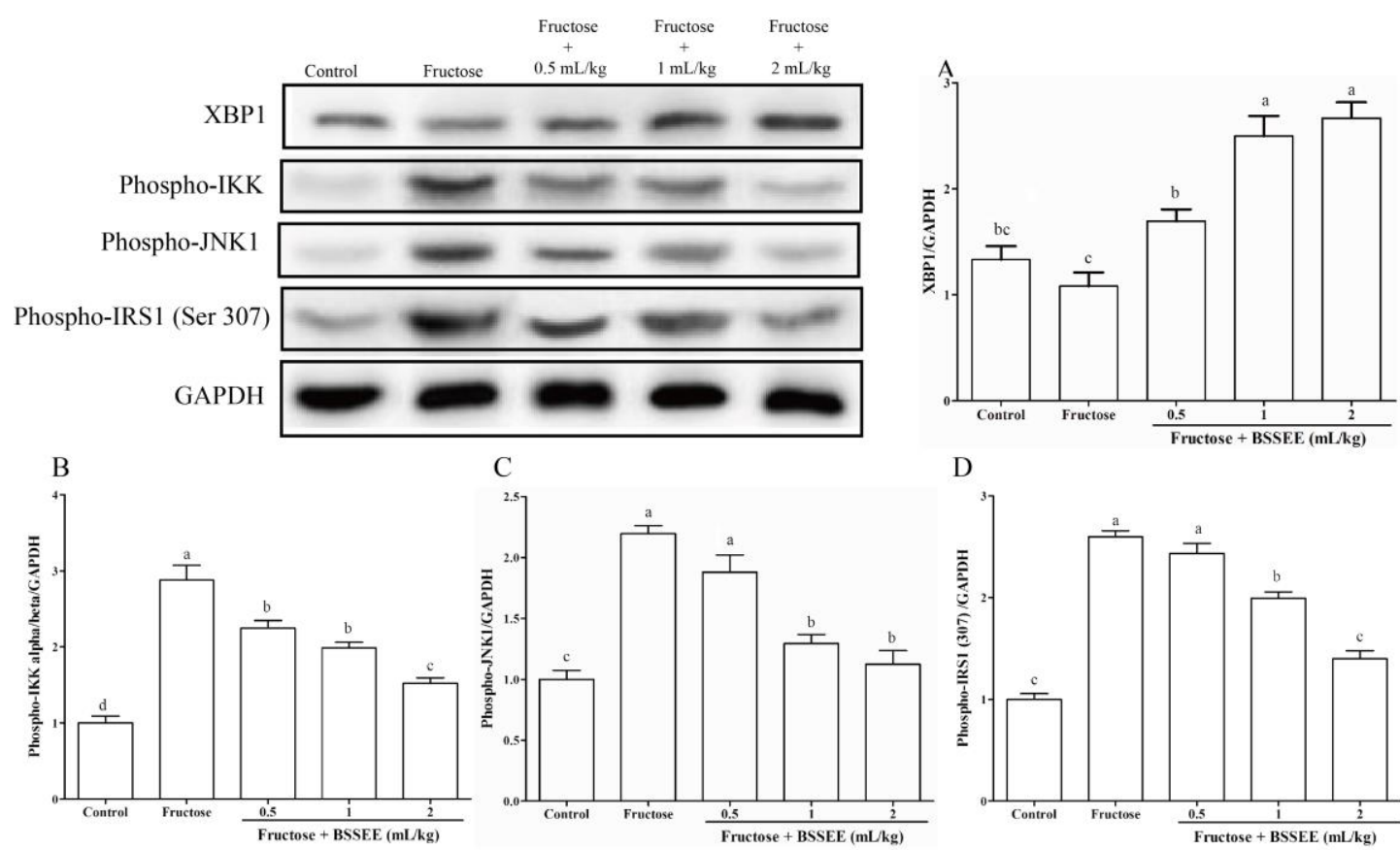

E
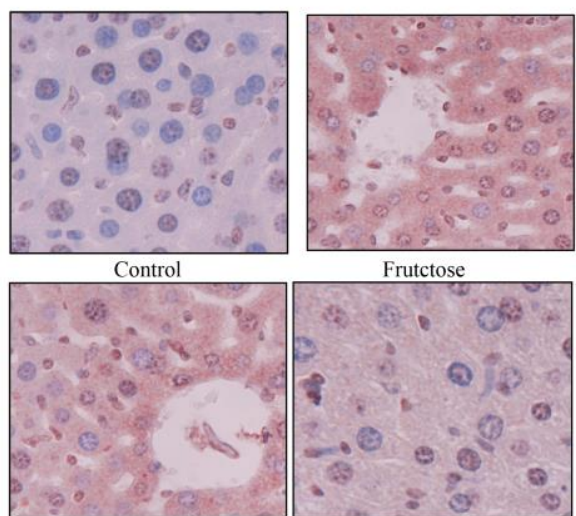

Frutctose
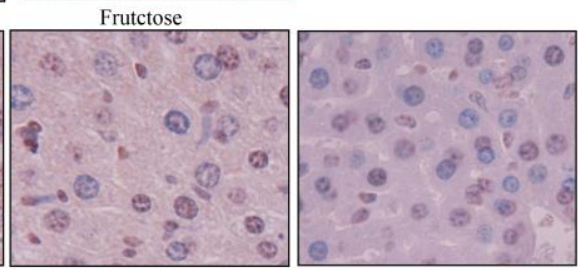

Fructose + BSSEE $(0.5 \mathrm{~mL} / \mathrm{kg}) \quad$ Fructose + BSSEE $(1 \mathrm{~mL} / \mathrm{kg}) \quad$ Fructose + BSSEE $(2 \mathrm{~mL} / \mathrm{kg})$

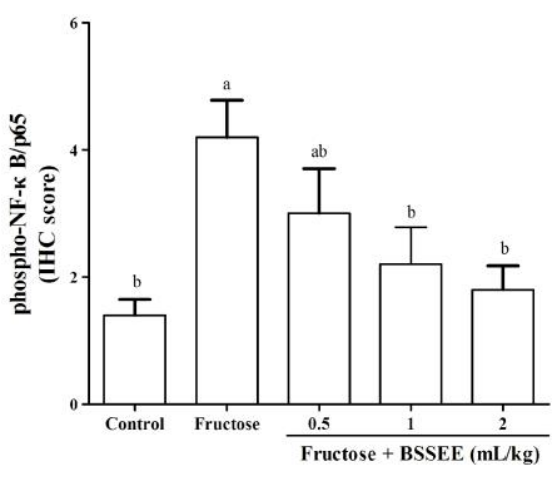

Figure.6. Effects of BSSEE (0.5, 1 and $2 \mathrm{~mL} / \mathrm{kg}$ ) on the expressions of hepatic (A) XBP1, (B) phospho-IKK, (C)

(E) The expression of phospho-NF- $\mathrm{B}$ p65 is analyzed by

immunohistochemistry (IHC) and semi-quantified in the fructose-fed mice and representative images are shown 
819 analyzed using one-way ANOVA coupled with Newman-Keuls's multiple-comparison test $(p<0.05)$.

\begin{tabular}{|c|c|c|c|c|c|c|c|}
\hline \multirow{2}{*}{ Groups } & \multicolumn{5}{|c|}{ Absolute weight (g) } & \multicolumn{2}{|c|}{ Relative weight (/body, \%) } \\
\hline & Liver & Perinephrit fat & Epididymal fat & Subcutaneous fat & Total fat & Liver & Total fat \\
\hline Control & $1.40 \pm 0.07 \mathrm{c}$ & $0.16 \pm 0.03 \mathrm{c}$ & $0.72 \pm 0.05 b$ & $0.82 \pm 0.05 \mathrm{c}$ & $1.71 \pm 0.06 \mathrm{c}$ & $3.28 \pm 0.25 \mathrm{c}$ & $4.03 \pm 0.15 \mathrm{~d}$ \\
\hline Fructose & $2.20 \pm 0.05 \mathrm{a}$ & $0.50 \pm 0.13 \mathrm{a}$ & $1.21 \pm 0.04 \mathrm{a}$ & $1.41 \pm 0.05 \mathrm{a}$ & $3.12 \pm 0.09 \mathrm{a}$ & $5.17 \pm 0.2 \mathrm{a}$ & $6.75 \pm 0.16 \mathrm{a}$ \\
\hline Fructose + BSSEE $(0.5 \mathrm{~mL} / \mathrm{kg})$ & $2.13 \pm 0.08 \mathrm{ab}$ & $0.37 \pm 0.06 \mathrm{~b}$ & $0.92 \pm 0.15 \mathrm{ab}$ & $1.12 \pm 0.18 \mathrm{ab}$ & $2.42 \pm 0.13 \mathrm{ab}$ & $4.98 \pm 0.15 \mathrm{ab}$ & $5.96 \pm 0.26 \mathrm{ab}$ \\
\hline Fructose + BSSEE $(1 \mathrm{~mL} / \mathrm{kg})$ & $1.80 \pm 0.04 \mathrm{bc}$ & $0.33 \pm 0.04 b$ & $0.80 \pm 0.06 \mathrm{~b}$ & $0.92 \pm 0.08 b c$ & $1.98 \pm 0.08 \mathrm{bc}$ & $4.65 \pm 0.13 \mathrm{bc}$ & $5.30 \pm 0.22 \mathrm{bc}$ \\
\hline Fructose + BSSEE $(2 \mathrm{~mL} / \mathrm{kg})$ & $1.50 \pm 0.07 \mathrm{c}$ & $0.25 \pm 0.08 \mathrm{bc}$ & $0.70 \pm 0.05 b$ & $0.85 \pm 0.07 \mathrm{c}$ & $1.87 \pm 0.09 \mathrm{c}$ & $3.82 \pm 0.19 \mathrm{c}$ & $4.36 \pm 0.24 \mathrm{~cd}$ \\
\hline
\end{tabular}

820

821

822

823

824

825

826

827

828

829

830

831 
833 Liquid intake, food intake and total energy intake show during BSSEE treatment. Cholesterol, triglycerides,

834 glucose, insulin, FFA, AST, ALT, TNF- $\alpha$ and IL-6 were measured in serum. Values are shown as means \pm SEM

$835(\mathrm{n}=10)$. Results were statistically analyzed using one-way ANOVA coupled with Newman-Keuls's

836 multiple-comparison test $(p<0.05)$.

\begin{tabular}{|c|c|c|c|c|c|}
\hline Group & Control & Fructose & Fructose + BSSEE $(0.5 \mathrm{~mL} / \mathrm{kg})$ & Fructose + BSSEE $(1 \mathrm{~mL} / \mathrm{kg})$ & Fructose + BSSEE $(2 \mathrm{~mL} / \mathrm{kg})$ \\
\hline Water consumption (mL/day) & $7.41 \pm 0.44 \mathrm{a}$ & $7.38 \pm 0.42 \mathrm{a}$ & $7.45 \pm 0.22 \mathrm{a}$ & $7.92 \pm 0.58 \mathrm{a}$ & $8.56 \pm 0.56 \mathrm{a}$ \\
\hline Average food intake ( $g /$ day) & $5.04 \pm 0.02 \mathrm{a}$ & $3.17 \pm 0.06 \mathrm{~b}$ & $3.02 \pm 0.17 \mathrm{bc}$ & $2.18 \pm 0.11 \mathrm{~d}$ & $2.22 \pm 0.15 \mathrm{~d}$ \\
\hline Total energy intake (kJ/day) & $20.78 \pm 0.07 \mathrm{a}$ & $22.73 \pm 1.05 \mathrm{a}$ & $22.36 \pm 1.08 \mathrm{a}$ & $19.86 \pm 1.06 \mathrm{a}$ & $20.78 \pm 1.16 \mathrm{a}$ \\
\hline Triglycerides $(\mathrm{mmol} / \mathrm{L})$ & $1.05 \pm 0.02 \mathrm{~b}$ & $2.17 \pm 0.13 \mathrm{a}$ & $2.07 \pm 0.23 \mathrm{a}$ & $1.42 \pm 0.11 \mathrm{~b}$ & $1.04 \pm 0.09 \mathrm{~b}$ \\
\hline Cholesterol (mmol/L) & $2.46 \pm 0.13 b$ & $3.74 \pm 23 \mathrm{a}$ & $2.24 \pm 0.04 \mathrm{~b}$ & $2.12 \pm 0.09 \mathrm{~b}$ & $2.04 \pm 0.10 \mathrm{~b}$ \\
\hline Glucose $(\mathrm{mmol} / \mathrm{L})$ & $7.63 \pm 0.64 b$ & $10.62 \pm 0.47 \mathrm{a}$ & $7.70 \pm 0.25 b$ & $7.33 \pm 0.23 b$ & $6.00 \pm 0.57 \mathrm{~b}$ \\
\hline Insulin (IU/L) & $16.40 \pm 1.45 \mathrm{bc}$ & $23.09 \pm 1.32 \mathrm{a}$ & $21.16 \pm 1.03 \mathrm{ab}$ & $16.85 \pm 1.68 \mathrm{bc}$ & $12.92 \pm 1.30 \mathrm{c}$ \\
\hline HOMA-IR & $4.96 \pm 0.21 \mathrm{bcd}$ & $11.15 \pm 0.65 \mathrm{a}$ & $7.1 \pm 0.42 \mathrm{~b}$ & $6.32 \pm 0.6 \mathrm{bc}$ & $3.49 \pm 0.0 .51 \mathrm{~d}$ \\
\hline $\mathrm{FFA}(\mathrm{mmol} / \mathrm{L})$ & $0.44 \pm 0.03 b$ & $0.54 \pm 0.01 \mathrm{a}$ & $0.52 \pm 0.01 \mathrm{a}$ & $0.41 \pm 0.03 \mathrm{~b}$ & $0.39 \pm 0.02 b$ \\
\hline AST (IU/L) & $81.60 \pm 4.37 \mathrm{~b}$ & $124.00 \pm 12.28 \mathrm{a}$ & $84.20 \pm 5.85 b$ & $79.50 \pm 6.50 \mathrm{~b}$ & $77.00 \pm 2.04 \mathrm{~b}$ \\
\hline ALT (IU/L) & $24.00 \pm 1.56 \mathrm{~b}$ & $38.80 \pm 3.96 \mathrm{a}$ & $27.00 \pm 2.81 \mathrm{~b}$ & $22.50 \pm 2.18 \mathrm{~b}$ & $20.50 \pm 1.32 b$ \\
\hline TNF- $\alpha(\mathrm{pg} / \mathrm{mL})$ & $61.85 \pm 3.81 \mathrm{~b}$ & $76.32 \pm 2.30 \mathrm{a}$ & $74.24 \pm 1.32 \mathrm{a}$ & $60.94 \pm 2.13 b$ & $55.28 \pm 3.77 \mathrm{~b}$ \\
\hline IL-6 $(\mathrm{pg} / \mathrm{mL})$ & $128.8 \pm 7.99 \mathrm{~b}$ & $164.4 \pm 7.84 \mathrm{a}$ & $152.5 \pm 5.68 \mathrm{a}$ & $122.6 \pm 4.80 \mathrm{~b}$ & $119.6 \pm 11.0 \mathrm{~b}$ \\
\hline
\end{tabular}

